Copyright (C) 2014 by Academic Publishing House Researcher

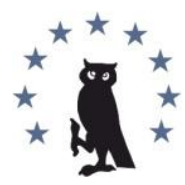

Published in the Russian Federation

European Researcher

Has been issued since 2010.

ISSN 2219-8229

E-ISSN 2224-0136

Vol. 86, No. 11-1, pp. 1885-1893, 2014

DOI: $10.13187 / \mathrm{er} .2014 .86 .1885$

www.erjournal.ru

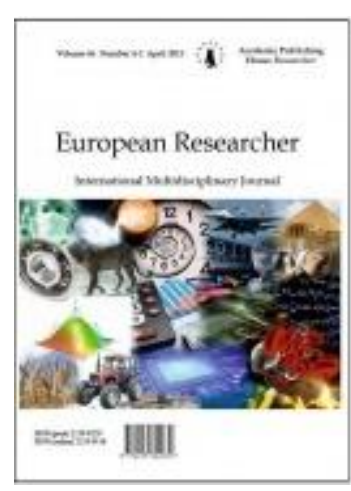

Engineering sciences

Технические науки

UDC 528; 004.9

\title{
Geo-Information Logistical Modeling
}

\author{
Nikolaj I. Kovalenko
}

Moscow State University of Railway Engineering, Russian Federation

PhD, Professor

E-mail: kni5o@mail.ru

\begin{abstract}
This paper examines geo-information logistical modeling. The author illustrates the similarities between geo-informatics and logistics in the area of spatial objectives; illustrates that applying geo-data expands the potential of logistics; brings to light geo-information modeling as the basis of logistical modeling; describes the types of geo-information logistical modeling; describes situational geo-information modeling as a variety of geo-information logistical modeling.

Keywords: geoinformatics; logistics; GIS technology; GIS technology logistics; situational modeling; digital simulation.

\section{Введение}

Геоинформатика и логистика имеют общее поле приложения пространственные объекты. Геоинформационное моделирование адаптивно, поскольку основано на интеграции технологий и методов моделирования. Поэтому уместно говорить о геоинформационном логистическом моделировании, в которое входит логистическое моделирование. Связующим элементом в геоинформатике являются пространственные отношения. Эти пространственные отношения часто принимают вид геореференций [1] В логистике пространственные отношения являются важнейшим фактором. Однако геореференций в ней пока практически не применяют. Еще один важный фактор применения геоинформатики - снижение рисков и информационной неопределенности при принятии управленческих решений [2].

Геоинформация и геоданные. Геоинформатика оперирует с геоинформацией, которая служит основой управления [3] и геоданными. Геоинформация и геоданные служат основой поддержки принятия решений [4]. Следует отметить, что геоинформация (Geoinformation) часто трактуется как Spatial information. Под этим термином понимают совокупность сведений и описаний об объектах и явлениях на земной поверхности, характеризуемая наличием пространственных отношений между этими явлениями и объектами.
\end{abstract}


Основным типом данных в геоинформатике являются геоданные [5], которые интегрируют многие данные. Современная логистика более бедна в аспекте использования данных. Геоданные включают в себя большее число параметров, чем традиционные логистические данные. Применение геоданных расширяет возможности логистики. Важным является интеграция трех групп геоданных данных «место», «время», «тема» в единую систему. Эта интеграция создает синергетический эффект, т.е. позволяет решать задачи, которые при разделении на отмеченные группы не решаются. Особенно важно это при решении логистических задач. Современная логистика использует пространственную информацию и нуждается в методах геоинформатики [6].

Основной информационной системой применяемой в геоинформатике является геоинформационная система (ГИС). ГИС может служить основой информационной логистической системы или быть дополнением к ней. Она может служить эффективным средством управления транспортом. Применение геоинформатики в логистике реализуется как комплекс технических и экономических исследований с целью решения логистических задач. Важной технологией в логистике является геоинформационное прогнозирование.

Применение геоинформатики в логистике. Говоря об особенностях применения геоинформатики в логистике, необходимо выделить наиболее важные тенденции развития геоинформатики и связать их с логистикой [7].

1. Переход от исследования объектов к исследованию систем в геоинформатике состоит в том, что современные методы геоинформатики основаны на системном подходе [8]. Он включает исследование не отдельного объекта, а исследование системы взаимосвязанных объектов, с учетом связей между ними и связей с внешней средой в которой они находятся. Для логистики эта тенденция важна, так как перемещение материальных потоков и отдельных объектов происходит в изменяющейся среде. Эти изменения системно позволяет учитывать геоинформатика

2. Переход от исследования отдельных явлений к исследованию комплексов в геоинформатике основан на интегрированном подходе [9]. Он включает построение интегрированных моделей при исследовании явлений и учета комплекса возможных факторов, которые влияют на исследуемое явление и тенденции его развития. Для логистики эта тенденция важна, так как перемещение материальных потоков и отдельных объектов происходит в изменяющейся среде, которая характеризуется комплексом факторов.

3. В геоинформатике применяют геоинформационный мониторинг [10], который служит основой многих видов технического и геотехнического мониторинг. Геомониторинг комплексов также основан на интегрированном подходе. Он включает сбор информации из различных источников и их интеграцию в единую интегрированную модель. На основе такой модели осуществляют анализ, прогнозирование и управление. В логистике пространственный мониторинг (геоинформационный мониторинг) применяют для контроля за движением грузов и объектов.

4. Тенденция перехода от цифровых карт к цифровым моделям в геоинформатике базируется на отказе применения плоских картографических моделей при расчетах и анализе, особенно протяженных объектов свыше 20 км [11]. Карта изначально представляет собой плоскую проекцию трехмерной поверхности. В силу этого она содержит ряд искажений реальной поверхности, которые возрастают при переходе к мелким масштабам. Цифровая модель изначально представляет собой трехмерную модель трехмерного объекта. При измерениях в геоцентрической системе она сохраняет привязку объекта к реальной поверхности земли и повторяет кривизну Земной поверхности в своих координатах.

5. Направление трехмерного моделирования тесно связано с использованием цифровых моделей. Классическое представление объектов в виде плоских карт или плоских чертежей не всегда позволяет отразить специфику объекта изысканий или соотнести его с окружающими объектами и местностью. Трехмерное моделирование позволяет рассматривать объект в реальной взаимосвязи с окружающей средой и принимать адекватное решение.

6. Направление дополнения стационарных технологий проектирования и обмена мобильными технологиями реализует концепцию он-лайн связи проектировщика при работе в натуре со стационарными комплексами или подразделениями. Которые находятся 
на значительном удалении от объекта изысканий или проектирования. Это направление связано с мобильными технологиями и технологиями беспроводного Интернета. В основе технической реализации лежит использование специальных компьютеров называемых нетбуками и мобильных средств связи $3 \mathrm{G}$ и более поздних поколений.

Рассмотрим некоторые методы и подходы геоинформатики, которые играют роль для логистического моделирования.

Визуальное моделирование является ключевым в представлении, интерпретации и моделировании пространственных данных. Учет пространственных отношений дает возможность находить слабые и сильные, явные и неявные связи между объектами, находящимися в разных точках пространства. Среди множества связей в геоинформатике одними из важных являются геореференцные связи [1]. Одной из процедур задания таких связей является геокодирование. Различают адресное, точечное и табличное геокодирование. При адресном геокодировании по адресу объекта определяют его метрические координаты. При точечном геокодировании по значениям координат в некой таблице помещают объекта точку местности, задаваемую этими координатами.

Использованием геостатистики применяется в первую очередь для ситуаций, имеющих вероятностные параметры или задаваемых неявно [12]. При таком подходе цифровая модель дополняется вероятностными характеристиками, отражающими размытость границ объекта или явления.

Применение методов и средств геоинформатики, позволяет проводить совместный пространственный анализ данных о состоянии природной среды и моделирования материальных потоков с использованием цифровых моделей, упрощает процедуры логистического прогнозирования и позволяет решать сложные задачи интермодальных перевозок.

Геоинформационное моделирование как основа логистического моделирования. Геоинформационное моделирование [13], как метод научного познания, прошло достаточно большой путь развития с момента становления геоинформатики. Своими корнями геоинформационное моделирование уходить в область информатики. В настоящее время есть основание проанализировать некоторые этапы развития этого моделирования и пересмотреть некоторые устаревшие подходы и принципы, и дать углубленную трактовку геоинформационного моделирования с учетом реалий.

Необходимо различать термины «геоинформационное моделирование» и «геомоделирование». Термин «геомоделирование» возник в геологии более 100 лет назад, задолго до появления геоинформатики. В настоящее время он применяется для обозначения моделирования в геологии, в геодинамике и в геодезии, а также для обобщенного моделирования в области наук о Земле. Его используют также для обозначения геоинформационного моделирования, однако на наш взгляд для корректности такого употребления нужен контекст. Правильнее использовать термин геоинформационное моделирование для исключения неоднозначности толкования общего термина «геомоделирование».

Геоинформационное моделирование включает построение пространственных моделей и различных манипуляций с этими моделями. Геоинформационное моделирование является методом отображения реального пространства и процессов, протекающих в нем. Моделирование в геоинформатике создает возможность переноса результатов, полученных в ходе построения и исследования моделей, на оригинал, и тем самым решает задачу извлечения знаний [14]. Применение геоинформационного моделирования в разных областях, особенно связанных с анализом реального пространства дает больший эффект, чем применение других видов моделирования.

Целью геоинформационного моделирования является либо «объяснение того, что есть», либо «прогнозирование того, что будет». Моделирование позволяет с меньшими затратами воссоздать процессы взаимодействия реального объекта и внешней среды и выявить критерии оптимизации этого взаимодействия. Особенностью геоинформационного моделирования является опора на пространственные отношения [15]. В настоящее время накоплен определенный опыт, который позволяет классифицировать это моделирование по разным аспектам. 
Основой геоинформационного моделирования являются геоданные и пространственные отношения. Общим для этих видов является использование трех интегрированных групп данных «место», «время», «тема». На практике пространственные отношения имеют четыре основных вида: иерархические, топологические, геореференцные [1] и геостатистические [12].

Иерархические пространственные отношения наиболее ярко проявляются в кадастре. В этой сфере имеет место четкая иерархия кадастровых объектов, которая используется на рынке недвижимости, при управлении землепользованием, в государственном управлении при учете природных и земельных ресурсов. Самым распространенным типом пространственных отношений при изучении пространственных объектов является иерархический тип, описывающий отношения между элементами, множествами и частями объектов. Это отношения «один ко многим»

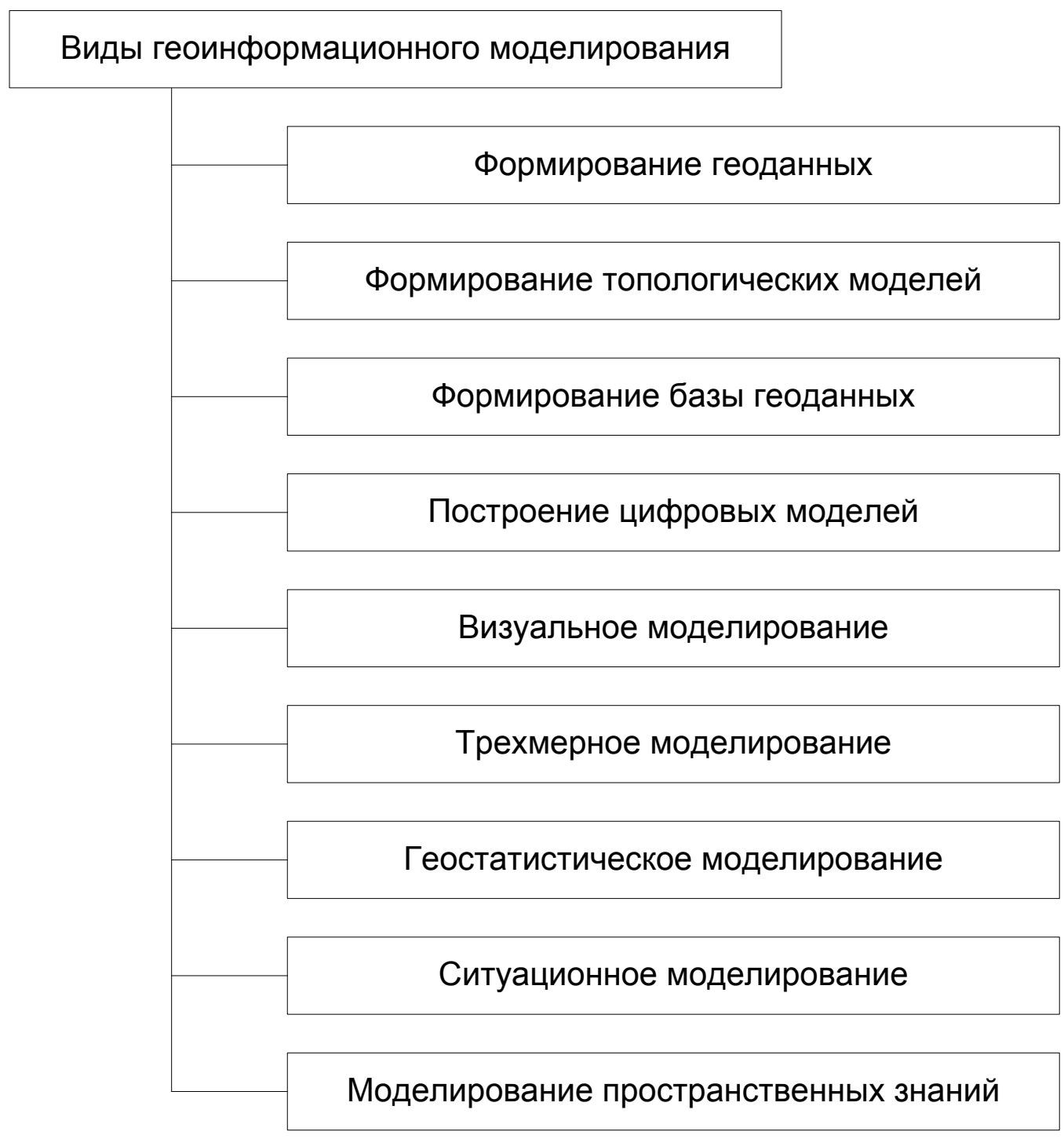

Puc. 1. Виды геоинформационного логистического моделирования

Виды геоинформационного логистического моделирования. Геоинформационное моделирование разнообразно. Геоинформационное логистическое моделирование основывается на геоинформационном и имеет структуру представленную на рис. 1. Первые три вида моделирования относятся к предобработке. По существу это моделирование на основе сбора первичной информации и построения интегрированной модели геоданных. В этом виде моделирования используют информационные технологии и 
могут обходиться без применения ГИС. Эти три вида направлены на снятие информационной неопределенности [16].

Построение цифровых моделей и визуальное моделирование являются обработкой, но служат основой для решения дальнейших задач. Следующие три вида: трехмерное моделирование, геостатистическое моделирование и ситуационное моделирование используются при решении прикладных задач.

Особое место занимает моделирование пространственных знаний. Оно осуществляется с целью изучения свойств пространственных объектов, исследования и получения пространственного знания. По мнению ряда зарубежных ученых, которое также отражено в Энциклопедии Британик, основной задачей геоинформатики является получение новых знаний.

Получение пространственных знаний развивалось за рубежом сначала в рамках искусственного интеллекта с 1960-х годов. С 1990-х годов эти исследования стали проводится совместно с методами геоинформатики. Геоинформационное логистическое моделирование не только одно из средств отображения явлений и процессов реального мира, но и объективный практический критерий проверки истинности знаний. Геоинформационное моделирование создает в итоге новые информационные модели и информационные ресурсы.

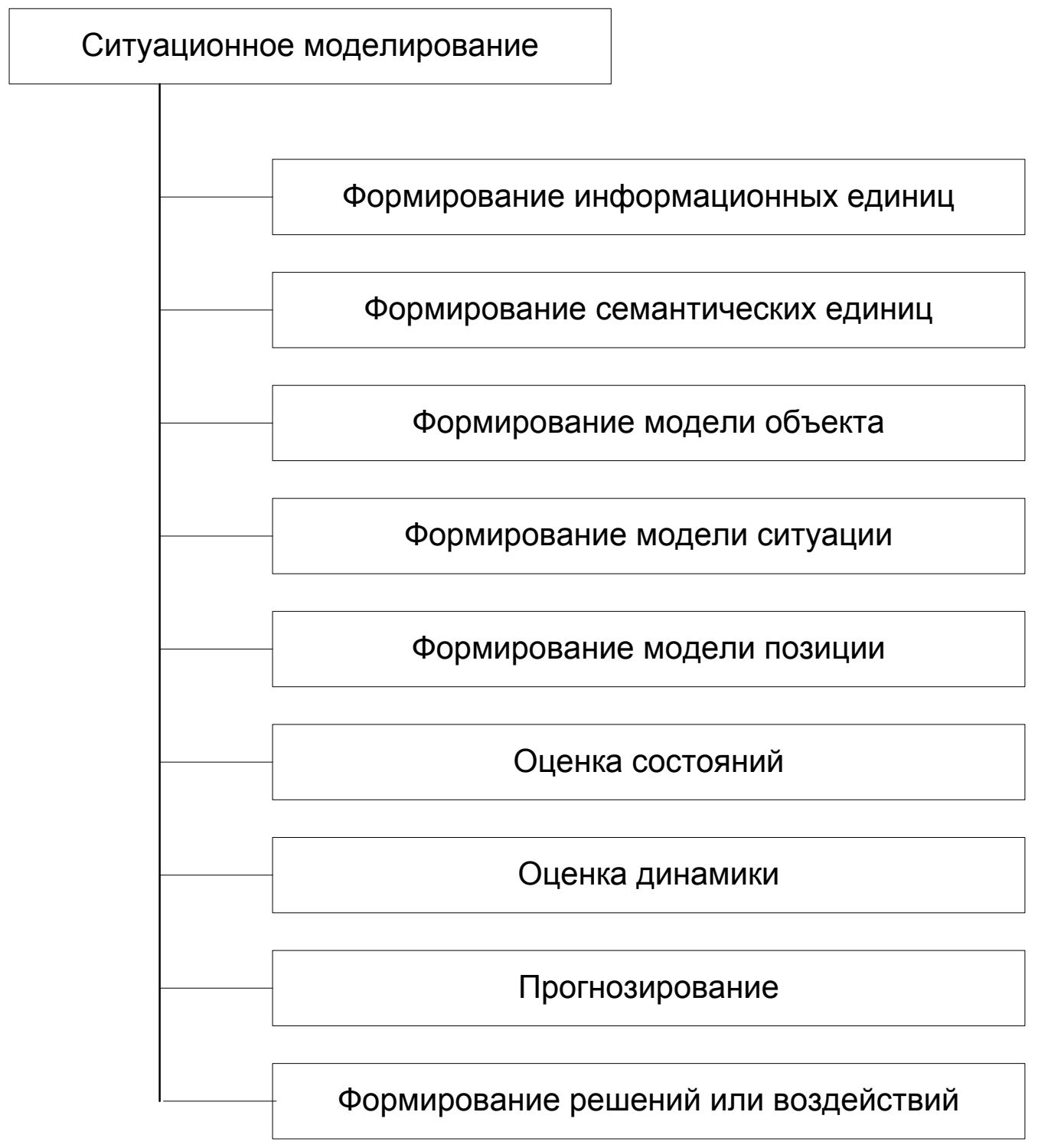

Puc. 2. Ситуационное геоинформационное моделирование 


\section{Ситуационное геоинформационное}

моделирование.

Ситуационное геоинформационное моделирование является также геоинформационным логистическим моделированием. Оно также решает логистические задачи, но в основном это задачи второго рода [17], которые не решаются с помощью одного алгоритма. Структурно ситуационное геоинформационное моделирование опирается на ряд специализированных моделей (рис.2). Значение ситуационного моделирования в том, что оно используется при поддержке принятия решений, при управлении и при управлении подвижными объектами, включая интеллектуальные транспортные системы и интеллектуальные логистические системы [18]. Это определяет тесную связь ситуационного моделирования и методов искусственного интеллекта.

Основой этого вида моделирования является построение модели информационной ситуации [19] и ее последующий анализ. Для построения модели информационной ситуации используют различные информационные единицы [20]. На основе информационных единиц формируются составные информационные модели объекта и ситуации.

Модели ситуаций включают пространственную, конфигурационную и позиционную составляющую. На основе анализа отношений модели объекта и модели ситуации формируется модель информационной позиции объекта в данной ситуации [21].

Понятие ситуации и позиции используется широко. Например ситуация и позиция в одном пространстве. Это может быть пространственная ситуация и пространственная позиция. Это может быть экономическая ситуация и экономическая позиция. Это может быть логистическая ситуации и логистическая позиция.

Возможны комбинации ситуаций и позиций. Например пространственная ситуация и экономическая позиция. Другой пример, пространственная ситуация плюс экологическая ситуация плюс логистическая позиция. В целом такие комбинации создают основу геоинформационного логистического моделирования

В геоинформационном логистическом моделировании широко применяют различные модели. Модели процессов включают динамические модели перемещения объектов и модели процессов, среди которых наиболее характерным является процессы управления, в частности подвижными объектами. В целом геоинформационное моделирование в совокупности с информационным подходом и информационным моделированием служит источником получения новых знаний. На основе этих моделей осуществляют прогноз и выработку управленческих решений

\section{Выводы}

Геоинформационное логистическое моделирование позволяет решать широкий круг задач, который нельзя решить с помощью других методов моделирования. Это обусловлено следующим.

1) геоинформационное моделирование использует широкий набор данных (место, время, тема), который в других технологиях не используют.

2) технологически геоинформационное моделирование является более широким в сравнении с другими видами моделирования, поскольку включает в единой среде моделирование ситуаций (пространственных и любых), объектов и процессов.

3) интеграция логистики в геоинформационные технологии создает синергетический эффект, за счет возможности использования пространственных отношений и геореференций.

4) геоданные, как основа моделирования в логистике представляют собой системный информационный ресурс [22]. Это дает возможность применения системного анализа и выявления системных свойств логистических операций и логистических систем.

5) геоинформационное логистическое моделирование хорошо формализовано и может быть выражено с помощью логических схем, что дает возможность применять методы вывода на основе прямой и обратной цепочки [23]. Это повышает надежность результатов и верифицируемость технологических решений.

В логистике геоинформационное моделирование является обязательным инструментом при решении пространственных задач и дополнительным инструментом для комбинированного решения пространственных и экономических задач. Результаты, получаемые с помощью геоинформационного логистического моделирования нельзя 
получить другими технологиями. В целом применение геоинформационного логистического моделирования позволит расширить методы, применяемые в логистике и решать новые задачи.

\section{Примечания:}

1. Майоров А.А., Цветков В.Я. Геореференция как применение пространственных отношений в геоинформатике // Известия высших учебных заведений. Геодезия и аэрофотосъемка. 2012. №3. с. 87-89.

2. Коваленко Н.И., Коваленко Н.А., Учёт неопределённости и риска в управлении железнодорожным транспортным комплексом // Вестник МГТУ МИРЭА «MSTU MIREA HERALD». 2014. № 3 (4), c. 189-194.

3. Маркелов В.М. Пространственная информация как фактор управления // Государственный советник. 2013. №4. с. 34-38.

4. Цветков В.Я. Применение геоинформационных технологий для поддержки принятия решений // Известия высших учебных заведений. Геодезия и аэрофотосъемка. 2001. №4. c. $128-138$.

5. Markelov V.M. Application Geodata in Logistics // European Researcher, 2012, Vol.(33), № 11-1. pp. 1835-1837.

6. Zyngier D., Kelly J. D. Multi-product inventory logistics modeling in the process industries //Optimization and logistics challenges in the enterprise. Springer US, 2009. C. 61-95.

7. Майоров А.А., Цветков В.Я., Маркелов В.М. Геоинформационный подход в логистике // Геодезия и аэрофотосъемка, 2012. №6. с. 93-97.

8. Tsvetkov V.Ya. Systems analysis in geoinformatics // European Journal of Technology and Design, 2013, Vol.(2), № 2, p. 135-140.

9. Геодезия, картография, геоинформатика, кадастр: Энциклопедия. В 2-х т. / Под ред. А.В. Бородко, В.П. Савиных. М.: ООО «Геодезкартиздат», 2008. Т. 1. 496 с.

10. Цветков В.Я. Геоинформационный мониторинг // Известия высших учебных заведений. Геодезия и аэрофотосъемка. 2005. №5. с. 151-155.

11. Дулин С.К., Якушев Д.А Автоматизированные дистанционные методы анализа состояния протяженных инфраструктурных объектов // Вестник МГТУ МИРЭА «MSTU MIREA HERALD» 2014. № 2 (3). c. 156-175.

12. Цветков В.Я. Геостатистика // Известия высших учебных заведений. Геодезия и аэрофотосъемка. 2007. №3. с. 174-184.

13. Цветков В.Я. Основы геоинформационного моделирования // Известия высших учебных заведений. Геодезия и аэрофотосъемка. 1999. №4. с. 147-157.

14. Коваленко Н.И. Извлечение знаний для интеллектуальных транспортных систем [Электронный ресурс] // Перспективы науки и образования. 2014. №5. с. 45-52. URL: http://pnojournal.wordpress.com/archive14/14-05/ (дата обращения: 10.11.2014).

15. Цветков В.Я. Виды пространственных отношений // Успехи современного естествознания. 2013. № 5. с. 138-140.

16. Коваленко Н.И. Учёт неопределённости при управлении транспортным комплексом // Государственный советник. 2014. №3. с. 50-54.

17. Цветков В.Я. Решение задач второго рода с использованием информационного подхода // Международный журнал прикладных и фундаментальных исследований. 2014. №11. (часть 2). с. 191-195.

18. Цветков В.Я., Маркелов В.М. Интеллектуализация логистики с применением геоинформатики // Международный журнал экспериментального образования. 2012. №6. c. 111-112.

19. Соловьев И.В. Применение модели информационной ситуации в геоинформатике // Науки о Земле. 2012. № 01. с. 54-58.

20. Tsvetkov V.Ya. Information Units as the Elements of Complex Models // Nanotechnology Research and Practice, 2014, Vol.(1), № 1. P. 57-64.

21. Tsvetkov V.Ya. Information Situation and Information Position as a Management Tool // European Researcher, 2012, Vol.(36), № 12-1, p. 2166-2170.

22. V.P. Savinykh and V. Ya. Tsvetkov Geodata As a Systemic Information Resource. ISSN 1019-3316, Herald of the Russian Academy of Sciences, 2014, Vol. 84, No. 5, pp. 365-368. 
23. Tsvetkov V.Ya. Conclusions of Intellectual Systems // Modeling of Artificial Intelligence. 2014. Vol.(3), № 3. pp. 138-148.

\section{References:}

1. Majorov A.A., Cvetkov V.Ja. Georeferencija kak primenenie prostranstvennyh otnoshenij v geoinformatike // Izvestija vysshih uchebnyh zavedenij. Geodezija i ajerofotos\#emka. 2012. №3. s. 87-89.

2. Kovalenko N.I., Kovalenko N.A., Uchjot neopredeljonnosti i riska $\mathrm{v}$ upravlenii zheleznodorozhnym transportnym kompleksom // Vestnik MGTU MIRJeA «MSTU MIREA HERALD» 2014. № 3 (4), s. 189-194.

3. Markelov V.M. Prostranstvennaja informacija kak faktor upravlenija // Gosudarstvennyj sovetnik. 2013. №4. S. 34-38.

4. Cvetkov V.Ja. Primenenie geoinformacionnyh tehnologij dlja podderzhki prinjatija reshenij // Izvestija vysshih uchebnyh zavedenij. Geodezija i ajerofotos\#emka. 2001. №4. s. 128138.5. Markelov V.M. Application Geodata in Logistics // European Researcher, 2012, Vol.(33), № 11-1. pp. 1835-1837.

6. Zyngier D., Kelly J. D. Multi-product inventory logistics modeling in the process industries //Optimization and logistics challenges in the enterprise. Springer US, 2009. C. 61-95.

7. Majorov A.A., Cvetkov V.Ja., Markelov V.M. Geoinformacionnyj podhod v logistike // Geodezija i ajerofotosemka, 2012. №6. s. 93-97.

8. Tsvetkov V.Ya. Systems analysis in geoinformatics // European Journal of Technology and Design, 2013, Vol.(2), № 2, p. 135-140.

9. Geodezija, kartografija, geoinformatika, kadastr: Jenciklopedija. V 2-h t. / Pod red. A.V. Borodko, V.P. Savinyh. M.: OOO «Geodezkartizdat», 2008. T. I. 496 s.

10. Cvetkov V.Ja. Geoinformacionnyj monitoring // Izvestija vysshih uchebnyh zavedenij. Geodezija i ajerofotosemka. 2005. №5. s. 151-155.

11. Dulin S.K., Jakushev D.A Avtomatizirovannye distancionnye metody analiza sostojanija protjazhennyh infrastrukturnyh obektov // Vestnik MGTU MIRJeA «MSTU MIREA HERALD» 2014. № 2 (3). s.156-175.

12. Cvetkov V.Ja. Geostatistika // Izvestija vysshih uchebnyh zavedenij. Geodezija i ajerofotosemka. 2007. №3. s. 174-184.

13. Cvetkov V.Ja. Osnovy geoinformacionnogo modelirovanija // Izvestija vysshih uchebnyh zavedenij. Geodezija i ajerofotosemka. 1999. №4. s. 147-157.

14. Kovalenko N.I. Izvlechenie znanij dlja intellektual'nyh transportnyh sistem [Jelektronnyj resurs] // Perspektivy nauki i obrazovanija-2014. №5. s. 45-52. URL: http://pnojournal. wordpress.com/archive14/14-05/ (data obrashhenija: 10.11.2014).

15. Cvetkov V.Ja. Vidy prostranstvennyh otnoshenij // Uspehi sovremennogo estestvoznanija. 2013. № 5. S. 138-140.

16. Kovalenko N.I. Uchjot neopredeljonnosti pri upravlenii transportnym kompleksom // Gosudarstvennyj sovetnik. 2014. №3. S. 50-54.

17. Cvetkov V.Ja. Reshenie zadach vtorogo roda s ispol'zovaniem informacionnogo podhoda // Mezhdunarodnyj zhurnal prikladnyh i fundamental'nyh issledovanij. 2014. №11. (chast' 2). S. 191-195.

18. Cvetkov V.Ja., Markelov V.M. Intellektualizacija logistiki s primeneniem geoinformatiki // Mezhdunarodnyj zhurnal jeksperimental'nogo obrazovanija. 2012. №6. s. 111-112.

19. Solov'ev I.V. Primenenie modeli informacionnoj situacii v geoinformatike // Nauki o Zemle. 2012. № 01. S. 54-58.20. Tsvetkov V.Ya. Information Units as the Elements of Complex Models // Nanotechnology Research and Practice, 2014, Vol.(1), № 1. P. 57-64.

21. Tsvetkov V.Ya. Information Situation and Information Position as a Management Tool // European Researcher, 2012, Vol.(36), № 12-1, p. 2166-2170.

22. V.P. Savinykh and V.Ya. Tsvetkov Geodata As a Systemic Information Resource. ISSN

1019-3316, Herald of the Russian Academy of Sciences, 2014, Vol. 84, No. 5, pp. 365-368.

23. Tsvetkov V.Ya. Conclusions of Intellectual Systems // Modeling of Artificial Intelligence. 2014. Vol.(3), № 3. pp. 138-148. 
УДК 528; 004.9

\section{Геоинформационное логистическое моделирование}

Николай Иванович Коваленко

Московский государственный университет путей сообщения, Российская Федерация Доктор технических наук, профессор

E-mail: kni5o@mail.ru

Аннотация. Дается анализ геоинформационного логистического моделирования. Показано сходство геоинформатики и логистики в области пространственных задач. Показано, что применение геоданных расширяет возможности логистики. Раскрыто геоинформационное моделирование как основа логистического моделирования. Описаны виды геоинформационного логистического моделирования. Описано ситуационное геоинформационное моделирование как разновидность геоинформационного логистического моделирования.

Ключевые слова: геоинформатика; логистика; геоинформационные технологии; геоинформационные логистические технологии; ситуационное моделирование; цифровое моделирование. 